\title{
Changes in pulmonary circulation in severe bronchopulmonary dysplasia
}

Brompton Hospital, Fulham Road, London SW3 6HP

A Bush

W B Knight

E A Shinebourne

Institute of Child Health, London

A A Hislop

S G Haworth

Correspondence to:

Dr Shinebourne.

Accepted 28 February 1990

\author{
A Bush, C M Busst, W B Knight, A A Hislop, S G Haworth, E A Shinebourne
}

\begin{abstract}
Eight patients with severe bronchopulmonary dysplasia underwent cardiac catheterisation. Seven had a pulmonary vascular resistance $>3 \mathrm{~mm} \mathrm{Hg} .1^{-1}$ min. $\mathrm{m}^{2}$ (mean 8.9, range 2.2 13.8). All had raised intrapulmonary shunts (mean $25.6 \%$, range $5.4-50 \%$, normal $<5 \%$ ). Two had a high alveolar dead space, and two had unsuspected congenital heart disease. Epoprostenol (prostacyclin), but not $100 \%$ oxygen, caused a significant fall in pulmonary vascular resistance. Death was associated with a high pulmonary vascular resistance and a high shunt. Morphometric studies in three cases showed normal numbers of airways, but increased thickness of bronchial muscle. The numbers of alveoli were reduced and the walls thickened. There was increased medial thickness in small pulmonary arteries with distal extension of muscle. In the oldest child some vessels were obliterated by fibrosis. We speculate that measurements of pulmonary vascular resistance and shunt may have prognostic value; that a trial of pulmonary vasodilators other than oxygen might be worthwhile in patients with poor prognosis; and that abnormalities of the pulmonary circulation contribute to the difficulties of managing patients with bronchopulmonary dysplasia.
\end{abstract}

The aggressive treatment of low birthweight, premature infants with respiratory distress has been extremely successful, but the cost has been that some survivors are left with chronic lung disease. Bronchopulmonary dysplasia was first described in $1967,{ }^{1}$ and is now increasingly recognised as a major cause of respiratory disability in infants. ${ }^{2} 3$ There have been many studies of airway function ${ }^{45}$ and lung mechanics,${ }^{67}$ but the cardiovascular consequences of bronchopulmonary dysplasia have received less attention, ${ }^{4-12}$ despite the recognition of the prognostic importance of cor pulmonale in the earliest descriptions of the disease. ${ }^{1}$

The Brompton Hospital is a tertiary referral centre for infants with severe bronchopulmonary dysplasia. Infants referred to the department of paediatric cardiology undergo cardiac catherterisation, mainly to exclude clinically important cardiac structural defects. At the same time we assess the response of the pulmonary circulation to vasodilators to see if they might be beneficial. We describe here the pulmonary haemodynamics and the abnormalities in gas exchange in this selected group, correlating them with quantitative lung morphology when possible.
Patients and methods

We studied eight infants who met the standard clinical diagnostic criteria for bronchopulmonary dysplasia, ${ }^{13}$ namely a respiratory disorder beginning with acute lung injury in the first two weeks of life; at least 28 days postnatal age; and appreciable clinical (tachypneoa, intercostal retraction), radiographic (hyperinflation, cystic areas, fibrotic strands), and functional (arterial oxygen pressure $\left(\mathrm{PaO}_{2}\right)<8 \mathrm{kPa}(60 \mathrm{~mm} \mathrm{Hg})$ or carbon dioxide pressure $\left(\mathrm{PaCO}_{2}\right)>6 \mathrm{kPa}$ $(45 \mathrm{~mm} \mathrm{Hg})$ while breathing air) abnormalities. These patients were referred consecutively from other hospitals during a three year period. The indication for referral was failure to improve clinically. Monitoring and treatment with oxygen, digoxin, and diuretics had been decided by the referring paediatricians and varied among the different referring centres. No patient had systemic hypertension. ${ }^{14}$ Informed consent by proxy was obtained from the parents in each case, and the procedures were approved by the Brompton Hospital ethics committee.

PHYSIOLOGICAL STUDIES

Full details of the methods have been published elsewhere. ${ }^{15}{ }^{16}$ Briefly, the infants were studied while they were anaesthetised, paralysed, and ventilated. We measured cardiac output by the direct Fick principle, and calculated pulmonary vascular resistance, wasted ventilation (alveolar dead space), and wasted perfusion (anatomical shunt). We assessed the fall in pulmonary vascular resistance in response to administration of $100 \%$ oxygen and to prostacyclin given intravenously.

For the calculations of cardiac output, oxygen consumption was measured by a mass spectrometer (MGA 200) using the steady state, argon dilution method. ${ }^{15}$ Blood oxygen contents were calculated from measured $\mathrm{PaO}_{2}, \mathrm{pH}$, and base excess (Corning 170 blood gas analyser), using Kelman's subroutine and assuming the solubility of free oxygen in blood to be $0.003 \mathrm{ml} / 100$ $\mathrm{ml} / \mathrm{mm} \mathrm{Hg} .{ }^{17}$ The mass spectrometer was also used to monitor end tidal gases to ensure a respiratory steady state was maintained throughout the study. End tidal $\mathrm{PCO}_{2}$ was calculated as the mean of at least eight measurements, which had to differ by less than $0.5 \mathrm{kPa}$ $(3.8 \mathrm{~mm} \mathrm{Hg})$.

Intravascular pressures were measured with fluid filled catheters introduced percutaneously into the femoral artery and vein and screened into position in the aorta and pulmonary artery, respectively. Pulmonary vascular resistance was calculated as (mean pulmonary artery 
pressure - mean left atrial pressure)/cardiac index. Pulmonary capillary wedge pressure was substituted for left atrial pressure where this could not be measured directly. In all cases this was less than $10 \mathrm{~mm} \mathrm{Hg}$, and did not change appreciably during the study. We also calculated the percentage of the alveolar dead space-that is, that part of the alveolar tidal volume (tidal volume minus the anatomical dead space) that reached alveoli which were not perfused-an index of wasted ventilation. The calculation is based on the Bohr equation, which gives percentage alveolar dead space equal to $\left[\left(1-\right.\right.$ end tidal $\left.\mathrm{PCO}_{2}\right) /$ arterial $\mathrm{PCO}_{2}$ $\times 100]$. Wasted perfusion (anatomical shunt on $100 \%$ oxygen) was calculated from the shunt equation $\left(\left[\mathrm{Cc}^{\prime} \mathrm{O}_{2}-\mathrm{CsaO}_{2}\right] /\left[\mathrm{Cc}^{\prime} \mathrm{O}_{2}-\mathrm{CpaO}_{2}\right]\right) \%$ where $\mathrm{Cc}^{\prime} \mathrm{O}_{2}, \mathrm{CsaO}_{2}, \mathrm{CpaO}_{2}$ are the blood oxygen contents of pulmonary end capillary, aortic, and mixed venous blood, respectively. Pulmonary end capillary $\mathrm{pO}_{2}$ was assumed to be within $1.3 \mathrm{kPa}(10 \mathrm{~mm} \mathrm{Hg})$ of alveolar $\mathrm{PO}_{2}$, which was calculated from the measured end tidal $\mathrm{PCO}_{2}$ using the alveolar air equation.

The initial measurements were made when the infants were ventilated on air, or the lowest inspired oxygen concentration that was considered safe. Respiratory steady state was confirmed by monitoring end tidal gases. The patients were then switched to $100 \%$ oxygen, and the measurements repeated after not less than 10 minutes ventilation. All other ventilator settings were constant during the study. Adequacy of alveolar nitrogen washout (mixed expired nitrogen $<1 \%$ ) was confirmed using the mass spectrometer. If the pulmonary vascular resistance on $100 \%$ oxygen was appreciably raised ( $>4$ units), prostacyclin was given by continuous infusion into a peripheral vein, initially at a dose of $5 \mathrm{ng} / \mathrm{kg} / \mathrm{min}$. The measurements were repeated at the end of five minutes. The dose was then increased by steps of $5 \mathrm{ng} / \mathrm{kg} /$ min, and measurements repeated after five minutes, until either a dose of $20 \mathrm{ng} / \mathrm{kg} / \mathrm{min}$ had been reached, or mean aortic pressure had fallen by $20 \mathrm{~mm} \mathrm{Hg}$. Finally the infusion was stopped, and diagnostic angiography carried out. We did not do pulmonary wedge angiograms.

PATHOLOGICAL STUDIES ON THE LUNG

Lung tissue was obtained at necropsy from cases $2,3,6$, and 8 . The initial necropsies were carried out at the referring hospitals, and no special preparation of the lungs was undertaken. The normal values were also taken from lung tissue that had not undergone special preparation. In each case at least four blocks of tissue were taken from different parts of the lung, and $4 \mu \mathrm{m}$ paraffin embedded sections were stained with haematoxylin and eosin, periodic acid Schiff's reagent, and Miller's elastic stain counterstained with van Geison's stain. Microscopically, the diameter and thickness of the muscle wall of the respiratory unit arteries and peripheral veins were measured with an eyepiece graticule. ${ }^{18}$ Percentage arterial wall thickness was calculated as: (twice the wall thickness/external diameter). The extension of muscle along the arterial pathway was determined. For the airways, the diameter of small bronchi and bronchioli was measured. The amount of bronchial wall muscle was estimated by planimetry using the Kontron MOP Videoplan image analyser, and expressed for each airway as area in $\mathrm{mm}^{2} / \mathrm{mm}$ length of lumen. The number of alveoli in the acinar region was estimated by calculating the Emery count. ${ }^{19}$

\section{Results}

There were four boys and four girls, mean age 12 months, range 10 weeks to 3 years (table 1 ). At the time of cardiac catherisation, cases 1-7 were being treated for cor pulmonale, which had been diagnosed on clinical grounds. All were receiving diuretics (frusemide and spironolactone) and cases $1-3$ and case 5 were receiving digoxin. There was only one long term survivor; cases $1,2,6$, and 7 died of progressive cardiorespiratory failure associated with presumed bronchopulmonary sepsis. In case 1, Candida albicans was isolated from the nasopharyngeal aspirate. In the other infants the diagnosis was a clinical one, but no pathogenic organisms were isolated. Case 3 died after aspirating a feed, and case 4 died in the intensive care unit of intractable pulmonary hypertension. The deaths were attributed to the complications of bronchopulmonary dysplasia, not to the haemodynamic studies. Case 8 , whose main problem was congenital heart disease, had surgical correction of the anomalous vena cava, but died after a stormy postoperative course complicated by recurrent pulmonary oedema, infection, and renal failure.

Table 1 Details of patients studied

\begin{tabular}{|c|c|c|c|c|c|c|c|}
\hline $\begin{array}{l}\text { Case } \\
\text { No }\end{array}$ & $\begin{array}{l}\text { Age } \\
\text { (years) }\end{array}$ & Sex & $\begin{array}{l}\text { Weight } \\
(\mathrm{kg})\end{array}$ & $\begin{array}{l}\text { Fractional inspired } \\
\text { oxygen concentration }\end{array}$ & $\begin{array}{l}\text { Electrocardiographic } \\
\text { findings }\end{array}$ & $\begin{array}{l}\text { Echocardiographic } \\
\text { findings }\end{array}$ & Type of ventilation \\
\hline 1 & $1 \cdot 1$ & Female & $3 \cdot 7$ & Air & $\begin{array}{l}\text { Right ventricular } \\
\text { hypertrophy }\end{array}$ & $\begin{array}{l}\text { Right ventricular } \\
\text { hypertrophy }\end{array}$ & Spontaneous \\
\hline 2 & 0.5 & Female & $4 \cdot 6$ & Low flow oxygen & $\begin{array}{l}\text { Right ventricular } \\
\text { hypertrophy }\end{array}$ & $\begin{array}{l}\text { Right ventricular } \\
\text { hypertrophy }\end{array}$ & Spontaneous \\
\hline 3 & $3 \cdot 5$ & Female & $8 \cdot 7$ & Air & $\begin{array}{l}\text { Right ventricular } \\
\text { hypertrophy }\end{array}$ & $\begin{array}{l}\text { Right ventricular } \\
\text { hypertrophy }\end{array}$ & Spontaneous \\
\hline 4 & 0.5 & Male & $3 \cdot 6$ & $1 \cdot 0$ & $\begin{array}{l}\text { Right ventricular } \\
\text { hypertrophy }\end{array}$ & $\begin{array}{l}\text { Right ventricular } \\
\text { hypertrophy }\end{array}$ & $\begin{array}{l}\text { Intermittent } \\
\text { positive pressure }\end{array}$ \\
\hline 5 & 0.8 & Male & $6 \cdot 3$ & Low flow oxygen & $\begin{array}{l}\text { Right ventricular } \\
\text { hypertrophy }\end{array}$ & $\begin{array}{l}\text { Right ventricular } \\
\text { hypertrophy and } \\
\text { ventricular septal } \\
\text { defect }\end{array}$ & Spontaneous \\
\hline 6 & $0 \cdot 2$ & Male & $2 \cdot 3$ & 0.6 & Normal & Normal & $\begin{array}{l}\text { Intermittent } \\
\text { positive pressure }\end{array}$ \\
\hline $\begin{array}{l}7 \\
8\end{array}$ & $\begin{array}{l}0.2 \\
1 \cdot 8\end{array}$ & $\begin{array}{l}\text { Male } \\
\text { Female }\end{array}$ & $\begin{array}{l}3 \cdot 7 \\
7 \cdot 9\end{array}$ & $\begin{array}{l}0 \cdot 3 \\
\text { Air }\end{array}$ & $\begin{array}{l}\text { Normal } \\
\text { Normal }\end{array}$ & $\begin{array}{l}\text { Normal } \\
\text { Normal }\end{array}$ & $\begin{array}{l}\text { Spontaneous } \\
\text { Spontaneous }\end{array}$ \\
\hline
\end{tabular}


PHYSIOLOGICAL STUDIES

The individual results are plotted in figs $1-3$. For the baseline measurements, mean (SD) $\mathrm{PaO}_{2}$ was $6.61(3.04) \mathrm{kPa}$ and $\mathrm{PaCO}_{2}$ was 4.45 $(0.83) \mathrm{kPa}$. All patients had raised anatomical shunts (mean $25 \cdot 6 \%$, range $5 \cdot 4-50 \cdot 0$, normal $5 \%)$. Two patients had high alveolar dead space, $26 \%$ and $30 \%$, respectively, the normal being $5 \%$. Seven patients had raised pulmonary vascular resistance (mean $8.8 \mathrm{~mm} \mathrm{Hg} .1^{-1} \cdot \min . \mathrm{m}^{2}$, range $2 \cdot 2-13 \cdot 8$, the normal being $<3$ units).

There were cardiac structural lesions in two

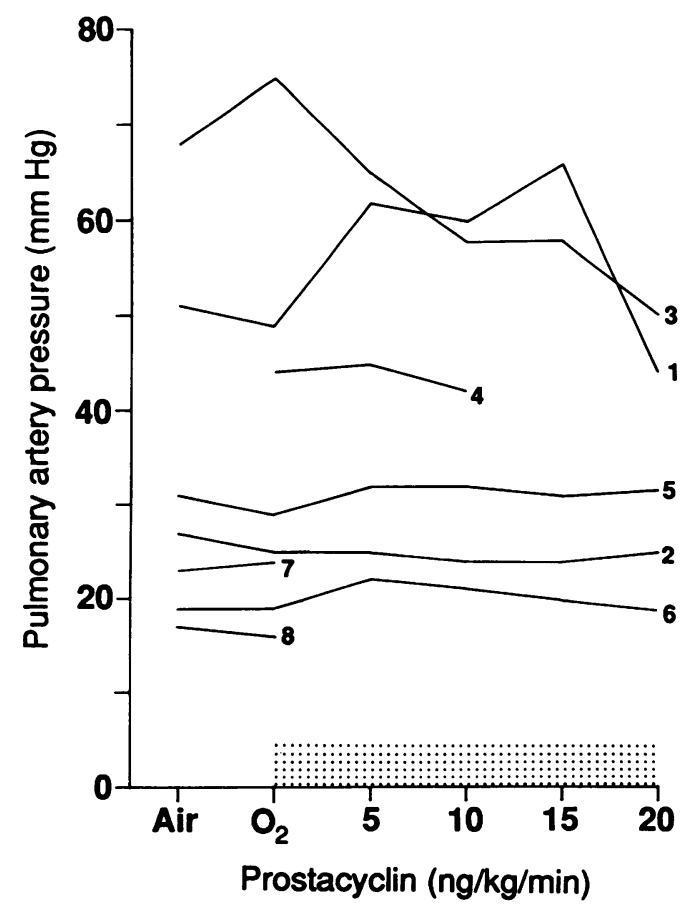

Figure 1 Individual changes in pulmonary artery pressure with $100 \%$ oxygen $\left(\mathrm{O}_{2}\right)$ and prostacyclin. The numbers correspond to the case numbers in table 1 . The baseline for cases 6 and 7 was not air, but fractional inspiratory oxygen of 0.6 and 0.3 , respectively.

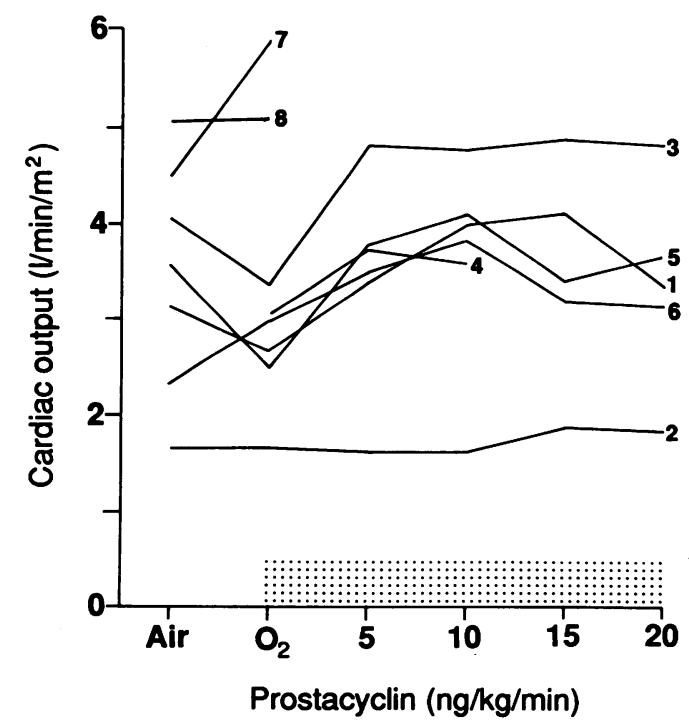

Figure 2 Individual changes in cardiac output with $100 \%$ oxygen $\left(\mathrm{O}_{2}\right)$ and prostacyclin. The numbers correspond to the case numbers in table 1 . The baseline for cases 6 and 7 was not air, but fractional inspiratory oxygen of 0.6 and 0.3 , respectively.

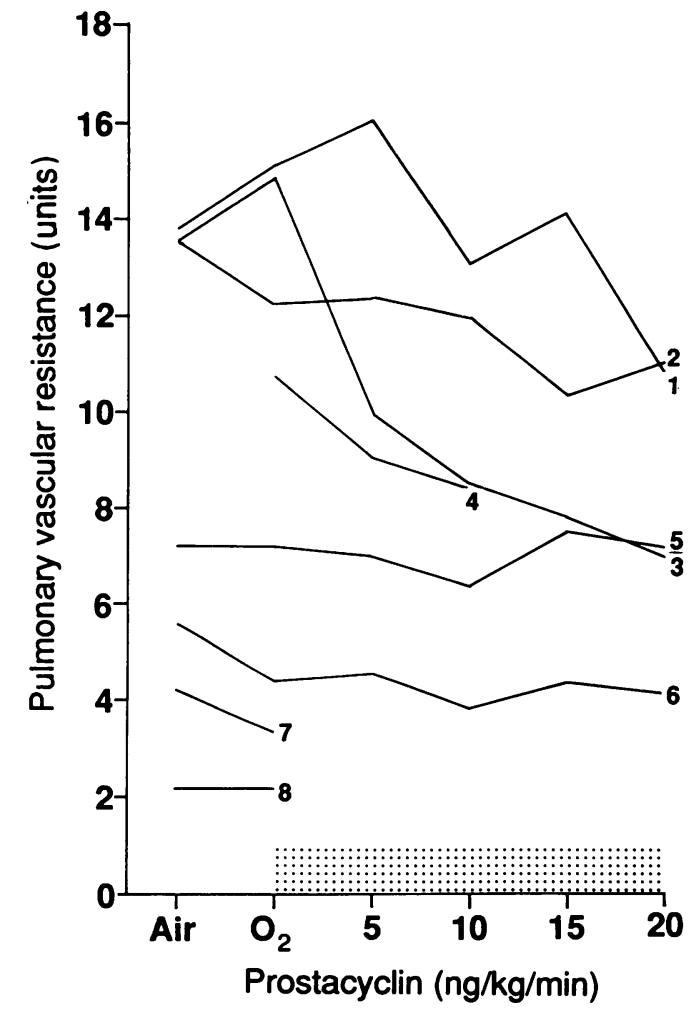

Figure 3 Individual changes in pulmonary vascular resistance with $100 \%$ oxygen $\left(\mathrm{O}_{2}\right)$ and prostacyclin. The numbers correspond to the case numbers in table 1 . The baseline for cases 6 and 7 was not air, but fractional inspiratory oxygen of 0.6 and $0 \cdot 3$, respectively.

patients. Case 5 had a small ventricular septal defect, which was haemodynamically unimportant. Case 8 had anomalous drainage of the superior vena cava into the left atrium, which almost totally accounted for the systemic arterial desaturation.

When switched to $100 \%$ oxygen, ventilation was comparable (mean (SD) $\mathrm{PaCO}_{2}=4.43$ $(1 \cdot 25) \mathrm{kPa})$ and $\mathrm{PaO}_{2}$ rose to $25 \cdot 51(17 \cdot 71) \mathrm{kPa}$. Mean pulmonary artery pressure showed little change except in case 3 , in whom it fell by 18 $\mathrm{mm} \mathrm{Hg}$. Cardiac output and pulmonary vascular resistance rose in two patients and fell in three others when they were given $100 \%$ oxygen. Group mean pulmonary vascular resistance was unchanged $(8 \cdot 8(4 \cdot 2))$. When prostacyclin was added, ventilation remained comparable $\left(\mathrm{PaCO}_{2}=4.56(1 \cdot 47)\right)$. Cardiac output rose in five of six patients and pulmonary vascular resistance fell in all patients. The changes in $\mathrm{PaO}_{2}$ are shown in fig 4. All patients showed rises when given $100 \%$ oxygen, but in two patients there were marked falls when they were given prostacyclin. These falls did not affect the blood oxygen content significantly, because the starting $\mathrm{PaO}_{2}$ was so high.

The group data are summarised in figs 5 and 6 . These results were prepared by removing the baseline variation and expressing the results as the percentage change over the measurement when breathing air. We selected the dose of prostacyclin that caused the maximum reduction in pulmonary vascular resistance. The values of the other variables at this dose of prostacyclin were then compared with the baseline 


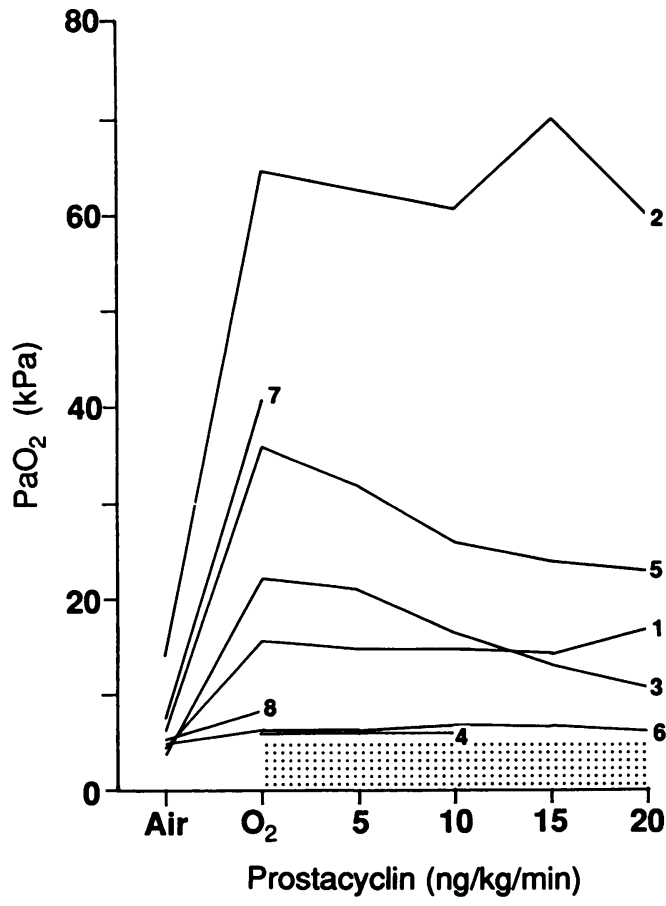

Figure 4 Individual changes in systemic arterial oxygen pressure $\left(\mathrm{PaO}_{2}\right)$ with $100 \%$ oxygen $\left(\mathrm{O}_{2}\right)$ and prostacyclin. The numbers correspond to the case numbers in table 1 . The baseline for cases 6 and 7 was not air, but fractional inspiratory oxygen of 0.6 and $0 \cdot 3$, respectively.

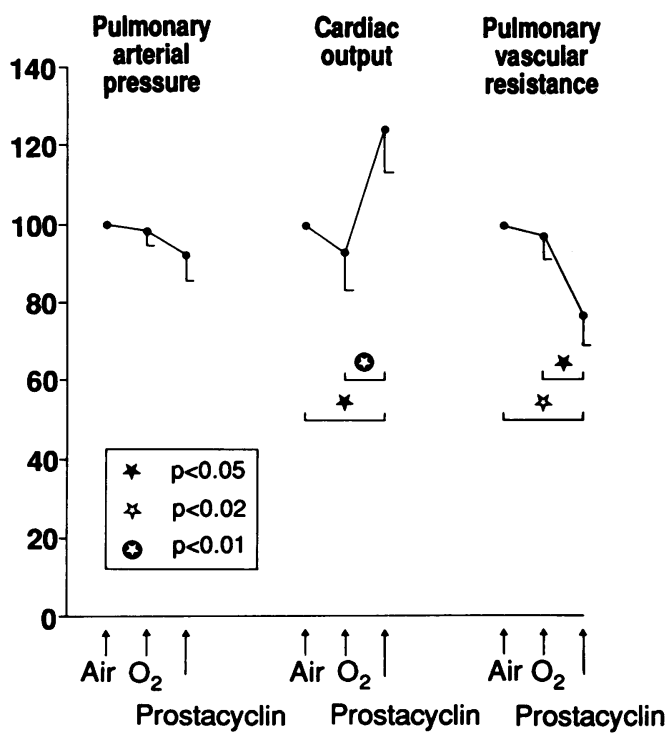

Figure 5 Percentage changes over baseline (vertical axis) in pulmonary haemodynamics with $100 \%$ oxygen $\left(\mathrm{O}_{2}\right)$ and the dose of prostacyclin resulting in the lowest pulmonary vascular resistance. There was no significant change in pulmonary artery pressure; cardiac output rose, and pulmonary vascular resistance fell when prostacyclin was given. These results are from the five patients with complete data for all doses of prostacyclin (case numbers $1-3,5$, and 6). Bar indicate mean (SEM) and significant differences are indicated.

measurement. Figure 5 shows that there was no significant change in pulmonary artery pressure at any time, and (for the group) no significant change in any variable when breathing $100 \%$ oxygen. Cardiac output (mean $(95 \%$ confidence intervals)) rose by $30.8(18.8$ to 42.8$) \%$ when prostacyclin was added to oxygen, and pulmonary vascular resistance fell by $23.2(9 \cdot 1$ to $37 \cdot 3) \%$. Prostacyclin also had effects on the sys-

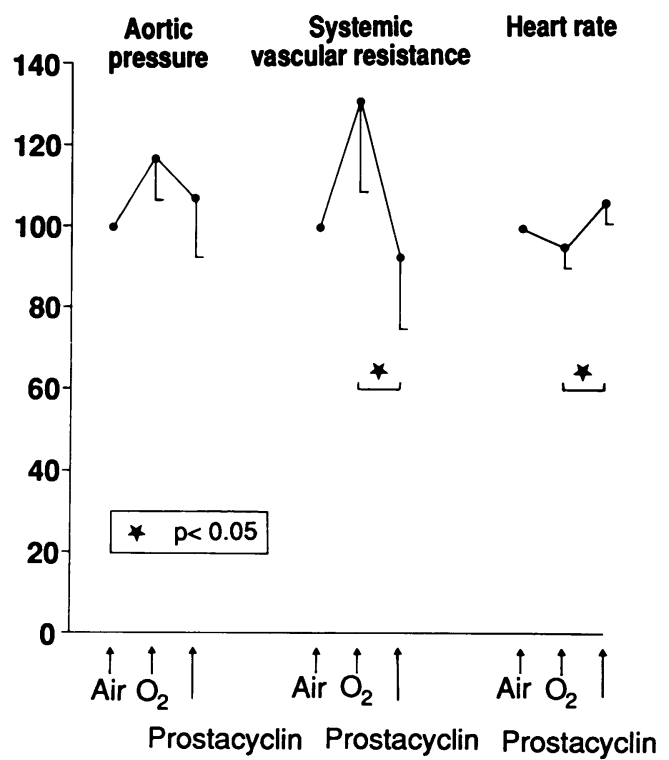

Figure 6 Percentage changes over baseline (vertical axis) in systemic haemodynamics with $100 \%$ oxygen $\left(\mathrm{O}_{2}\right)$ and the dose of prostacyclin resulting in the lowest pulmonary vascular resistance. There was no significant change in aortic pressure: systemic vascular resistance fell, and heart rate rose, when prostacyclin was given. These results are from the five patients with complete data for all doses of prostacyclin (case numbers 1-3, 5, and 6). Bars indicate mean (SEM) and significant differences are indicated.

temic circulation (fig 6). There was no change in aortic pressure, but systemic vascular resistance fell by $38.8(13.8$ to $63 \cdot 8) \%$, and heart rate rose by $11.0(3.9$ to $18 \cdot 1) \%$, when prostacyclin was added to oxygen; from these data, there was no evidence for any selective effect on the pulmonary circulation.

Of the six patients who died with severe bronchopulmonary dysplasia (cases $1-4,6$, and 7), two had pulmonary vascular resistance of more than 7 units, two had anatomical shunts of more than $30 \%$, and two had both these abnormalities. Both patients with wasted ventilation of more than $25 \%$ died.

\section{PATHOLOGICAL STUDIES}

In cases 2, 3, and 6 the structure of the peripheral airways and alveoli was abnormal, the alveoli varying in size and shape. The alveolar walls were thickened with an excess of collagen and elastin, and in cases 2 and 3 capillary density seemed to be increased. In all three cases, an Emery count indicated a reduction in alveolar number (table 2). In the oldest, aged 3 years, the alveolar count was similar to the normal value at birth. The peripheral airways were of normal size for age, but the amount of bronchial smooth muscle was increased. There were no areas of extensive fibrosis. In the vasculature, pulmonary arterial smooth muscle was increased, as shown by a significant increase in mean percentage arterial medial thickness and by extension of muscle into more peripheral arteries than normal so that most of the alveolar wall arteries were completely muscularised (table 2, fig 7). Only the oldest case showed intimal proliferation, with hyalinisation of the 
Table 2 Results of pathological studies

\begin{tabular}{|c|c|c|c|c|c|c|}
\hline \multirow[t]{2}{*}{$\begin{array}{l}\text { Case } \\
\text { No }\end{array}$} & \multirow[t]{2}{*}{$\begin{array}{l}\text { Age at } \\
\text { death (years) }\end{array}$} & \multicolumn{2}{|c|}{$\begin{array}{l}\text { Percentage arterial wall } \\
\text { thickness }\end{array}$} & \multirow[t]{2}{*}{$\begin{array}{l}\text { Percentage vein wall } \\
\text { thickness }(50-100 \mu)\end{array}$} & \multirow[t]{2}{*}{$\begin{array}{l}\text { Emery } \\
\text { count }\end{array}$} & \multirow[t]{2}{*}{$\begin{array}{l}\text { Bronchial muscle } \\
\left(\mathrm{mm}^{2} / \mathrm{mm} \text { length of lumen }\right)\end{array}$} \\
\hline & & $<100 \mu$ & $\geqslant 100 \mu$ & & & \\
\hline $\begin{array}{l}2 \\
3 \\
6 \\
8\end{array}$ & $\begin{array}{l}1 \cdot 3 \\
3 \cdot 5 \\
0 \cdot 6 \\
2 \cdot 0\end{array}$ & $\begin{array}{l}17 \cdot 9^{* * *} \\
31 \cdot 2^{* * *} \\
15 \cdot 5^{* * *} \\
13 \cdot 4^{* * *}\end{array}$ & $\begin{array}{l}22 \cdot 9 * * * \\
24 \cdot 3^{* * *} \\
9 \cdot 6^{* * *} \\
9 \cdot 4^{* * *}\end{array}$ & $\begin{array}{l}5 \cdot 0 \\
6 \cdot 6^{*} \\
5 \cdot 9^{*} \\
6 \cdot 3^{* *: * k}\end{array}$ & $\begin{array}{l}5 \cdot 0 \\
5 \cdot 7 \\
4 \cdot 7 \\
7 \cdot 4\end{array}$ & $\begin{array}{l}0 \cdot 005 \\
0 \cdot 007 \\
0 \cdot 013 \\
0 \cdot 003\end{array}$ \\
\hline \multicolumn{2}{|c|}{$\begin{array}{l}\text { Normal values: } \\
\text { Babies born at full term } \\
\text { aged } 0-24 \text { hours } \\
\text { Infants aged } 8 \text { months } \\
\text { to } 3 \text { years }\end{array}$} & $\begin{array}{r}24 \cdot 9^{18} \\
9 \cdot 6^{18}\end{array}$ & $\begin{array}{r}14 \cdot 7^{18} \\
7 \cdot 2^{18}\end{array}$ & $\begin{array}{l}4 \cdot 7^{18} \\
4 \cdot 7^{18}\end{array}$ & $\begin{array}{l}5 \cdot 5^{19} \\
8 \cdot 5^{19}\end{array}$ & $\begin{array}{l}0.0015 t \\
0.0045 t\end{array}$ \\
\hline
\end{tabular}

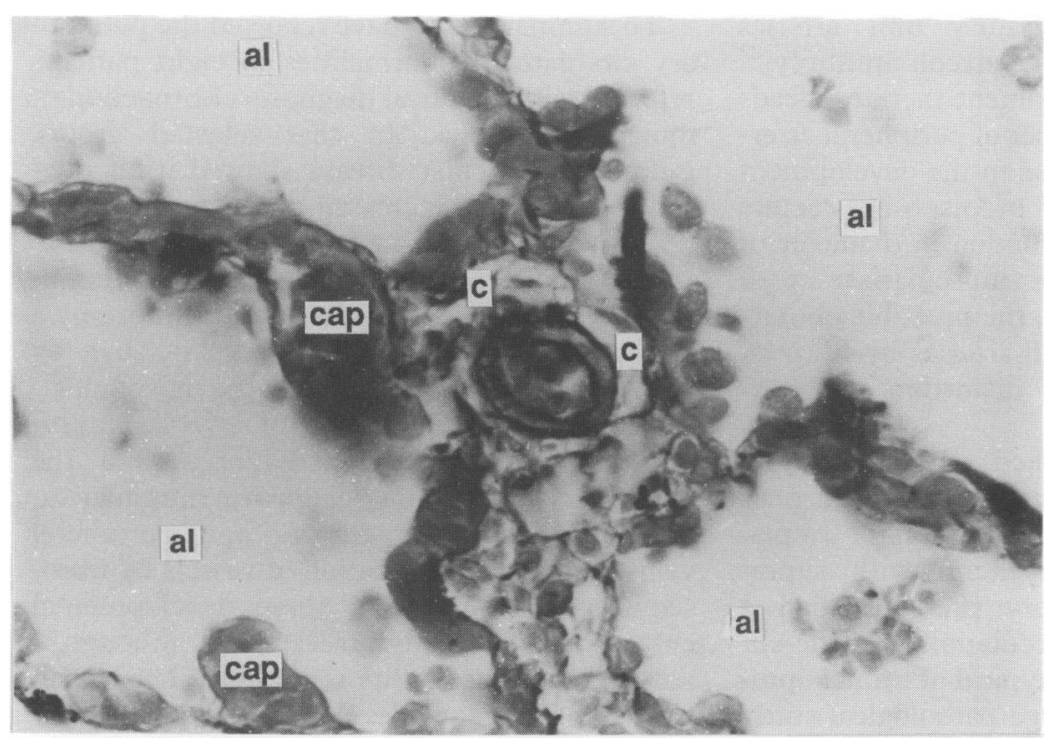

Figure 7 Photomicrograph of necropsy lung tissue from case 3 stained with Miller's elastic stain and van Gieson's stain magnification $\times 720$. A muscular pulmonary artery (wall thickness $30 \%$ ) is seen at the junction of alveoli. Abbreviations: cap =capillary, al=alveolus, and $c=$ collagen. severity of heart and lung disease. This patient is not discussed further. The main findings in the other seven patients were increases in pulmonary vascular resistance $(n=7)$, anatomical shunt $(n=2)$, and alveolar dead space $(n=2)$. In this selected group of patients, prostacyclin was a better pulmonary vasodilator than oxygen. The patients with pulmonary vascular resistance of greater than 7 units, or anatomical shunt of more than $30 \%$, or both $(n=6)$, died from their disease. Quantitative histology $(n=3)$ showed reduced numbers of alveoli with thickened walls. There was increased medial muscle thickness in small pulmonary arteries, and distal extension of smooth muscle. The changes tended to be more severe with increasing age and pulmonary vascular resistance, although there were too few infants for statistical testing.

The physiological study compared the pulmonary vascular reactivity to oxgyen and prostacyclin. We chose prostacyclin because we had previously shown it to be a safe pulmonary vasodilator in children with congenital heart disease. ${ }^{16}$ Oxygen has been reported to lower pulmonary vascular resistance in some but not all patients with bronchopulmonary dysplasia. ${ }^{10} 11$ In our selected group of patients, oxygen had no acute effects on pulmonary haemodynamics, whereas prostacyclin caused a pronounced fall in pulmonary vascular resistance. Other workers have reported falls in pulmonary vascular resistance in patients with bronchopulmonary dysplasia given hydralazine. ${ }^{12}$ We recommend extreme caution, however, if prostacyclin or other bloodborne pulmonary vasodilators are to be used. Case 4 was unable to tolerate a dose higher than $10 \mathrm{ng} / \mathrm{kg} /$ min because of systemic hypotension. Prostacyclin caused a fall in systemic vascular resistance in all patients, and a fall in $\mathrm{PaO}_{2}$ in two. Hydralazine may also cause adverse reactions in patients with bronchopulmonary dysplasia. ${ }^{12}$ Under controlled conditions, bloodborne pulmonary vasodilators may be useful adjuncts to management, and possibly allow reductions in inspired oxygen tension, one of the major aetiological factors in bronchopulmonary dysplasia.

The structural study showed that in three cases the abnormalities of the airways consisted of a failure of alveolar multiplication with an increase in both the amount of bronchial smooth muscle, and in the amounts of collagen and elastin within the alveolar walls. These abnormalities of airways were no more severe,

\begin{abstract}
cardiac structural lesion, and histology lung confirmed only minor changes of bronchopulmonary dysplasia. Similar diagnostic difficulties have been reported by others, ${ }^{911}$ and it may be difficult to assess clinically the relative

Discussion

We have reported eight patients who were sent to a tertiary referral centre with a diagnosis of severe bronchopulmonary dysplasia. One
\end{abstract}


however, than those reported, in a previous series of children who also had neonatal respiratory distress and who subsequently did not develop cor pulmonale. ${ }^{21}$ This difference in natural history is not explained by bronchoalveolar changes alone. Neither group of patients had the extensive fibrosis described in the classic accounts of bronchopulmonary dysplasia. ${ }^{122}$ Such severe damage is now rarely seen, probably because of improvements in methods of mechanical ventilation.

Cor pulmonale is usually associated with alveolar hypoxia in adults and children, but in our cases failure of alveolar development was probably an important additional factor. In normal children new respiratory unit arteries develop after birth as the alveoli multiply. ${ }^{23}$ Failure of alveolar development therefore leads to a reduction in the number of peripheral arteries, which would predipose to the development of cor pulmonale. Other predisposing factors include a pronounced reduction in diameter of the lumens by excessive muscularisation of small precapillary arteries, the probable obliteration of some alveolar wall arteries by fibrosis, and possibly also capillary distortion by abnormally shaped alveoli.

There are few published data correlating pulmonary haemodynamics with lung morphology in infants with bronchopulmonary dysplasia. A single premature infant with suprasystemic pulmonary artery pressures had a hypoplastic pulmonary circulation, but the clinical course had not been typical of bronchopulmonary dysplasia. ${ }^{24} \mathrm{~A}$ large pathological study confirmed that hypertensive pulmonary vascular disease is common in bronchopulmonary dysplasia, ${ }^{25}$ but no haemodynamic data were available. In contrast to our study and to the findings of others, ${ }^{25} 26$ one group reported increased numbers of small pulmonary arteries with medial wall thicknesses that were less than normal ${ }^{27}$; we cannot account for these discrepancies.

Although ours is a small series, the severity of the pulmonary arterial changes tended to increase with age, as shown by the progressive increase in pulmonary vascular smooth muscle, and the presence of some hyalinised arteries in the oldest child. Correlation between structure and function is difficult because of the small number of cases and the relatively long time interval (up to nine months) between cardiac catheterisation and death in these young patients. The wasted perfusion might be the result of collagen deposition in the alveolar walls, and possibly also in the blood gas barrier. ${ }^{28}$ Wasted ventilation could be attributed to a reduction in peripheral pulmonary arterial number and the diameters of the lumens.

These data were obtained from a highly selected subgroup of patients with bronchopulmonary dysplasia, but may have implications for the outpatient treatment of less severely affected patients. The current mainstay of treatment is domiciliary oxygen. ${ }^{29} 30$ Treatment with an oral pulmonary vasodilator would be much more convenient than low flow oxygen. Theoretically it may even be safer, in that there is some evidence that even modest increases in inspired oxygen tensions may be toxic. ${ }^{31}{ }^{32}$ Any fall in $\mathrm{PaO}_{2}$ would be dangerous, however, in patients who have arterial hypoxaemia while breathing air, because a large fall in blood oxygen content would result. Possibly the combination of low flow oxygen and an oral vasodilator might be more useful than either alone. If they are to affect the natural history of the disease appreciably, however, they would probably have to be given much earlier, before the pulmonary circulation became irreversibly damaged. Any such treatment should be the subject of a carefully controlled trial before it could be recommended for general use.

To summarise, we have reported the pulmonary circulatory abnormalities in eight patients referred with a clinical diagnosis of bronchopulmonary dysplasia. In this selected group, pulmonary vascular disease showed itself physiologically by an increased pulmonary vascular resistance and by disturbances of ventilation to perfusion matching. The increases in pulmonary vascular resistance were reduced more by a bloodborne vasodilator, prostacyclin, than by $100 \%$ oxygen. In these patients the morphological counterpart was failure of alveolar multiplication and consequent hypoplasia of the pulmonary circulation, extensive muscularisation of precapillary arteries and peripheral veins, and some obliteration of vessels by fibrosis in case 6. Most of these developmental changes are probably irreversible, although a reduction in muscularity is possible. The reason why some patients develop severe pulmonary vascular disease secondary to bronchopulmonary dysplasia is not clear. We suggest that cardiac catheterisation should be carried out more readily in patients with bronchopulmonary dysplasia. It is important to exclude cardiac structural lesions, and hyperinflation may make echocardiography difficult. Cardiac catheterisation may also help to choose the most effective treatment for the individual patient. In addition, we need to increase our understanding of the role of the pulmonary circulation in the pathogenesis of this condition.

AB, AAH, and SGH were supported by the British Heart Foundation.

1 Northway WH, Rosan RC, Porter DY. Pulmonary disease following respiratory therapy of hyaline-membrane disease. $N$ Engl $f$ Med 1967;276:357-68.

2 Greenough A, Roberton NRC. Morbidity and survival in neonates ventilated for the respiratory distress syndrome. Br Med F 1985;290:597-600.

3 Bancalari E, Gerhardt T. Bronchopulmonary dysplasia. Pediatr Clin North Am 1986;33:1-23.

4 Harrod JR, L'Heureux P, Wangenstein OD, Hunt CE. Long-term followup of severe respiratory distress syndrome treated with IPPB. F Pediatr 1974;84:277-86.

5 Smyth JA, Tabachnik E, Duncan WJ, Reilly BJ, Levison H. Pulmonary function and bronchial hyperreactivity in longterm survivors of bronchopulmonary dysplasia. Pediatrics 1981;68:336-40.

6 Bryan MH, Hardie MJ, Reilly BJ, Swyer PR. Pulmonary function studies during the first year of life in infants recovering from respiratory distress syndrome. Pediatrics 1973;52:169-78.

7 Tepper RS, Pagtakhan RD, Taussig LM. Non-invasive determination of total respiratory system compliance in infants by the weighted-spirometer method. Am Rev Respir Dis 1984;130:461-6

8 Berman W, Yabek SM, Dillon T, Burstein R, Corlew S. Evaluation of infants with bronchopulmonary dysplasia using cardiac catheterization. Pediatrics 1982;70:708-12. diopulmonary abnormalities complicating bronccted cardiopulmonary abnormalities complicating bronch

10 Abman SH, Wolfe RR, Accurso FJ, Koops BL, Bowman 
CM, Wiggins JW. Puilmonary vascular response to oxygen in infants with severe bronchopulmonary dysplasia. Pediatrics 1985;75:80-4.

11 Berman W, Katz R, Yabek SM, Dillon T, Fripp RR, Papille LA. Long-term follow-up of bronchopulmonary dysplasia. Pediatr 1986;109:45-50.

12 Goodman G, Perkin RM, Anas NG, Sperling DR, Hicks DA, Rowen $M$. Pulmonary hypertension in infants with bronchopulmonary dysplasia. $\mathcal{\exists}$ Pediatr 1988;112:67-72.

13 O'Brodovich HM, Mellins RB. Bronchopulmonary dysplasia. Am Rev Respir Dis 1985;132:694-709.

14 Abman SH, Warachy BA, Lum GM, Koops BL. Systemic hypertension in infants with bronchopulmonary dysplasia. $\mathcal{f}$ Pediatr 1984;104:929-31.

15 Davies NJH, Denison DM. The measurement of metabolic gas exchange by mass spectrometry alone. Respir Physiol 1979;36:261-7.

16 Bush A, Busst CM, Booth K, Knight WB, Shinebourne EA Does prostacyclin enhance the selective pulmonary vasodilator effect of oxygen in children with congenital heart disease? Circulation 1986;74:135-44.

17 Kelman GR. Digital computer subroutine for the conversion of oxygen tension into oxygen saturation. $\mathcal{f}$ Appl Physiol $1966 ; 21: 1375-6$

18 Haworth SG, Hislop AA. Pulmonary vascular development normal values of peripheral vascular structure. Am $\mathfrak{J}$ Cardiol 1983;52:578-83.

19 Emery JL, Mithal $A$. The number of alveoli in the termina respiratory unit of man during late intrauterine life and childhood. Arch Dis Child 1960;35:544-7. 20 Wagenvoort CA. Morphologic changes in the intrapulmonary

21 Hislop A, Wigglesworth JS, Dessai R, Aber V. The effects of preterm delivery and mechanical ventilation on human lung growth. Early Hum Dev 1987;15:147-64.

22 Taghizadeh A, Reynolds EO Pathogenesis of bronchopulmonary dysplasia following hyaline membrane disease. Am monary dysplasia following

23 Hislop A, Reid L. Pulmonary arterial development during childhood: branching pattern and structure. Thorax 1973; 28:129-35

24 Rendas A, Brown ER, Avery ME, Reid LM. Prematurity, hypoplasia of the pulmonary vascular bed, and hypertension: fatal outcome in a ten month old infant. Am Rev Respir Dis 1980;121:873-80.

25 Stocker JT. Pathologic features of long-standing 'healed' bronchopulmonary dysplasia. A study of 28 3- to 40month-old infants. Hum Pathol 1986;17:943-61.

26 Sobonya RE, Logvinoff MM, Taussig LM, Theriault A. Morphometric analysis of the lung in prolonged bronchopulmonary dysplasia. Pediatr Res 1982;16:969-72.

27 Tomashefski JF Jr, Opperman HC, Vawter GF. Bronchopulmonary dysplasia: a morphometric study with emphasis on monary dysplasia: a morphometric study with emphasis on

28 Haworth SG, Hall SM, Patel M. Peripheral pulmonary vascular and airway abnormalities in adolescents with rheumatic lar and airway abnormalities in adolescents with

29 Pinney MA, Cotton EK. Home management of bronchopulmonary dysplasia. Pediatrics 1976;58:856-9.

30 Campbell AN, Zarfin Y, Groenveld M, Bryan MH. Low flow therapy in infants. Arch Dis Child 1983;58:795-8.

31 Boat TH, Kleinerman JI, Fanarff AA, Matthews LW. Toxic effects of oxygen on cultured human neonatal respiratory epithelium. Pediatr Res 1973;7:607-15.

32 Nunn JF. Oxygen - friend and foe. F R Soc Med 1985;78: 